\title{
Detecting protein-protein interactions with GFP-fragment reassembly
}

\author{
Christopher GM Wilson ${ }^{1}$, Thomas J Magliery ${ }^{1}$ \& Lynne Regan $^{1,2}$
}

${ }^{1}$ Department of Molecular Biophysics and Biochemistry, Yale University, P.O. Box 208114, New Haven, Connecticut 06520-8114, USA.

${ }^{2}$ Department of Chemistry, Yale University, P.O. Box 208107, New Haven, Connecticut 06520-8107, USA.

The detection of protein-protein interactions in vivo is of critical importance to our understanding of biological processes. The classic library approach has been to use the yeast two-hybrid screen, where an interaction between known bait and unknown prey proteins leads to restoration of transcription factor activity ${ }^{1}$. However, its use is limited by host organism and nuclear localization requirements, and a tendency to detect indirect interactions ( false positives). Bacterial two-hybrid screens have eliminated localization requirements and simplified many technical aspects of the procedure ${ }^{2}$. An innovative approach has been the reassembly of protein fragments, which then directly report interactions. A suitable reporter protein is dissected at the genetic level, and the fragments are fused to bait and prey, which are then coexpressed in vivo. Bait and prey interaction brings the reporter fragments together, facilitating reassembly of the active reporter protein, giving a direct readout of the association. This method has been demonstrated for dihydrofolate reductase ${ }^{3,4}$, ubiquitin ${ }^{5}$ and the green fluorescent protein6 (GFP) from Aequorea victoria We recently described improvements to the original screen based on the reassembly of the GFP enhancedstability mutant sg100 in Escherichia coli ${ }^{7}$. Our system, presented in the protocol that follows, consists of two plasmid vectors for the independent expression of fusions with $\mathrm{N}$ - and C-terminal fragments of GFP, and allows for simple visual detection of protein-protein interactions with a $K^{D}$ as weak as $1 \mathrm{mM}$.

\section{MATERIALS}

REAGENTS

Plasmid vectors pET11a-link-NGFP and pMRBAD-link-CGFP and positive control vectors pET11a-Z-NGFP and pMRBAD-Z-

CGFP are available upon request (Fig. 1)

Primers for cloning into pET11a-link-NGFP and pMRBAD-link-CGFP (Fig. 1)

Selective media: LB containing $100 \mu \mathrm{g} / \mathrm{ml}$ ampicillin and LB containing $35 \mu \mathrm{g} / \mathrm{ml}$ kanamycin

Restriction enzymes: NcoI, BamHI, AatII, XhoI, XmaI and SphI (New England Biolabs (NEB))

Thermostable DNA polymerase (for example, Deep Vent Polymerase, NEB)

dNTP solution $(10 \mathrm{mM})$

Calf intestinal alkaline phosphatase (NEB)

T4 DNA ligase (NEB)

E. coli strains DH10B and BL21 (DE3), prepared as competent cells (preferably electrocompetent)

Sequencing primers for pET11a-link-NGFP (T7 terminator primer $5^{\prime}$-tatgctagttattgctcag- $3^{\prime}$ ) and pMRBAD-link-CGFP (5'ctactgtttctccatacccg- $\left.3^{\prime}\right)$

ExoSAP-IT (USB)

Screening medium: for $250 \mathrm{ml} \mathrm{LB}$ agar (for about ten plates) add $250 \mu \mathrm{l}$ of $10 \mathrm{mM}$ IPTG, $2.5 \mathrm{ml}$ of $20 \%$ arabinose, $250 \mu \mathrm{lof} 100 \mathrm{mg} /$ $\mathrm{ml}$ ampicillin $(100 \mu \mathrm{g} / \mathrm{ml})$ and $250 \mu \mathrm{l}$ of $35 \mathrm{mg} / \mathrm{ml}$ kanamycin $(35 \mu \mathrm{g} / \mathrm{ml})$. Sterilize all additives by passing through a $0.2 \mu \mathrm{m}$ filter. Lysis buffer: $50 \mathrm{mM}$ Tris $\mathrm{HCl}$, pH 8.0, $300 \mathrm{mM} \mathrm{NaCl}, 10 \mathrm{mM}$ imidazole, $0.1 \%$ Triton X-100, $1 \mathrm{mg} / \mathrm{ml}$ lysozyme, $0.5 \mathrm{mM} \mathrm{CaCl}_{2}, 5$ $\mathrm{mM} \mathrm{MgCl}$

Nucleases: DNase and RNase (Sigma)

Ni-NTA agarose (Qiagen)

Wash buffer: $50 \mathrm{mM}$ Tris $\mathrm{HCl}$, $\mathrm{pH}$ 8.0, $300 \mathrm{mM} \mathrm{NaCl}, 20 \mathrm{mM}$ imidazole

\section{EQUIPMENT}

Thermal cycler programmed with the desired amplification protocol

Handheld long-wave UV lamp (365 nm)

Disposable standing column (Bio-Rad) 
Preparation of vectors encoding the fusion proteins

\section{PROCEDURE}

1| To prepare the cloning vectors, transform separately pET11a-link-NGFP and pMRBAD-link-CGFP into an E. coli strain that gives high-quality plasmid DNA (for example, DH10B or XL1-Blue) and plate onto selective agar media. Select for cells carrying the pET1la constructs in the presence of $100 \mu \mathrm{g} / \mathrm{ml}$ ampicillin and for those carrying pMRBAD constructs with $35 \mu \mathrm{g} / \mathrm{ml}$ kanamycin. Prepare plasmid DNA using standard miniprep protocols.

PMRBAD-link-CGFP transformations must be incubated with shaking at $37^{\circ} \mathrm{C}$ for $1 \mathrm{~h}$ before they are plated on selective media.

\section{$\triangle$ CRITICAL STEPS}

$\rightarrow$ TROUBLESHOOTING

2| To prepare vectors pET1la-link-NGFP and pMRBAD-link-CGFP for cloning, set up the following reactions for double digestion:

Reaction 1

Reaction 2

pET11a-link-NGFP

$1 \mu \mathrm{g}$

NEB buffer 4 BamHI

$5 \mu \mathrm{l}$

$100 \times B S A$

$0.5 \mu \mathrm{L}$

$1 \mu \mathrm{l}$

Xhol (20 units)

$1 \mu l$

Water to

$\begin{array}{ll}\text { PMRBAD-link-CGFP } & 1 \mu \mathrm{g} \\ \text { NEB buffer } 4 & 5 \mu \mathrm{l} \\ \text { 100× BSA } & 0.5 \mu \mathrm{l} \\ \text { Ncol (20 units) } & 2 \mu \mathrm{l} \\ \text { AatlI (20 units) } & 1 \mu \mathrm{l} \\ \text { Water to } & 50 \mu \mathrm{l}\end{array}$

Figure 1 | GFP-fragment reassembly vectors and cloning linker sequences. (a) Oligonucleotide linker sequences for amplification of target bait and prey DNA. NGFP in-frame fusions are made through the Xhol site in the forward primer sequence. The reverse primer should contain a stop codon followed by a BamHI site. Cloning into PMRBAD-link-CFGP requires a forward primer in frame with the ATG in the Ncol site. Fusion to CGFP is achieved through the in-frame Aatll site primer sequence. The symbol (xxx) represents codons of the template gene to be amplified and cloned into the vectors. Six codons (18 bp) are usually sufficient to obtain specific amplification of most target sequences. The six-base extension ( $5^{\prime}$-aataat) is required for efficient cutting by restriction enzymes. (b) Cloning linker sites and key features of the GFP-fragment vectors. pET11a-link-GFP contains the ampicillin resistance marker $\left(A p^{R}\right)$ and ColE1 origin of replication (ori). The Xmal site in the linker is lost during cloning; thus, digestion with Xmal can be used to eliminate the background that results from religation. Fusion expression is achieved in a BL21 DE3 host with the addition of IPTG, which results in transcription from the $T 7$ promoter $\left(\mathrm{P}_{\mathrm{T7}}\right)$. The rop gene product regulates the copy number of plasmids containing the ColE1 origin of replication, and the lacl gene product, the Lac repressor, reduces leaky expression in DE3 bacterial hosts. pMRBAD-link-GFP contains the kanamycin resistance gene $\left(\mathrm{Kn}^{\mathrm{R}}\right)$ and $\mathrm{p} 15 \mathrm{~A}$ origin of replication. The linker Sphl site is lost during cloning; thus, digestion with Sphl can be used to eliminate the background that results from religation. Fusion expression is under the control of the $\mathrm{P}_{\mathrm{BAD}}$ promoter (regulated by the product of the araC gene) and is induced with $\mathrm{L}-(+)$-arabinose. Note that the resulting GFP fusions have different orientations relative to the GFP fragment, which may affect the likelihood of successful GFP reassembly. Sequence details of these vectors can be found in Supplementary Note online and at http:// www.csb.yale.edu/ people/ regan/ publications.html. The structures of the vectors can be found in Supplementary Fig. 1 online. 
Incubate the reactions at $37^{\circ} \mathrm{C}$ for $3 \mathrm{~h}$, adding $1 \mu$ l of calf intestinal alkaline phosphatase (10 units) for the final $30 \mathrm{~min}$.

\section{$\Rightarrow$ TROUBLESHOOTING}

3| Purify the vector products by electrophoresis through $0.8-1 \%$ agarose and determine the concentration of vector DNA by measuring UV absorbance at $260 \mathrm{~nm}$ or by running an aliquot on an agarose gel.

We purify the DNA by electrophoresis through Whatman glass fiber filter paper (GF/C) onto dialysis membrane, but commercial methods (for example, gel solubilization and extraction procedures) are acceptable. Ethanol-precipitate the DNA before ligation to concentrate the sample and remove salts that can interfere with ligation. The amount of vector obtained is usually sufficient to perform two 260 -ng $(\sim 0.05-\mathrm{pmol})$ ligations.

4| Set up an amplification reaction to prepare each of the inserts, incorporating the appropriate linker sequences (Fig. 1a) to produce in-frame GFP-fragment fusions:

Depending on the composition of the amplification buffer, additional $\mathrm{Mg}^{2+}$ may be required for template DNA above 1 kilobase (kb).

\section{For a $\mathbf{5 0} \mu$ l reaction:}

\begin{tabular}{ll}
\hline Template DNA & $0.1 \mathrm{ng}$ \\
Primer (each) & $100 \mathrm{pmol}$ \\
10× amplification buffer & $5 \mu \mathrm{l}$ \\
dNTP solution & $5 \mu \mathrm{l}$ \\
Thermostable DNA polymerase & $1 \mu \mathrm{l}$
\end{tabular}

Alternatively, small inserts ( $<150$ base pairs, bp) can be prepared synthetically, by annealing two oligonucleotides and extending with Klenow DNA polymerase. It is critical that the digested fragments produce in-frame fusions ( see Fig. 1b).

$\triangle$ CRITICAL STEPS

\section{TROUBLESHOOTING}

5| Amplify the nucleic acids according to the following program:

Times and temperatures are optimized for a 1-kb template but may need to be adapted to suit the particular reaction conditions. For example, the duration of the polymerization step should be $1 \mathrm{~min} / \mathrm{kb}$ for Deep Vent DNA polymerase.

\begin{tabular}{llll}
\hline Cycle number & Denaturation & Annealing & Polymerization \\
\hline $1-30$ & 1 min at $95^{\circ} \mathrm{C}$ & $30 \mathrm{~s}$ at $55^{\circ} \mathrm{C}$ & $1 \min$ at $72^{\circ} \mathrm{C}$ \\
Last & & $5 \min$ at $72^{\circ} \mathrm{C}$ \\
\hline
\end{tabular}

6| To purify the amplification products, extract each reaction once with phenol/chloroform/ isoamyl alcohol (25: 24:1, v/v/v) and then with chloroform/isoamyl alcohol $(29: 1, \mathrm{v} / \mathrm{v})$ and recover the DNA by precipitation with ethanol.

Analyze the size and quality of the products by electrophoresis through an agarose gel.

7| To prepare the inserts for cloning, digest $1 \mu \mathrm{g}$ of insert DNA of the appropriate vector as described in step 2, omitting the calf intestinal alkaline phosphatase treatment. 
8) Set up the reactions for ligation of inserts into vectors, by mixing $0.05 \mathrm{pmol}$ of vector with 0.05 pmol of insert ( $260 \mathrm{ng}$ pET11a-link-NGFP and $150 \mathrm{ng}$ pMRBAD-link-CGFP per reaction):

\begin{tabular}{ll}
\hline Doubly digested, dephosphorylated vector DNA (step 2) & $0.05 \mathrm{pmol}$ \\
Doubly digested insert DNA (step 7) & $0.05 \mathrm{pmol}$ \\
10x ligase buffer & $1.0 \mu \mathrm{l}$ \\
DNA ligase (400 units) & $0.5 \mu \mathrm{l}$ \\
Water & to $10 \mu \mathrm{l}$ \\
\hline
\end{tabular}

Incubate reactions at $16^{\circ} \mathrm{C}$ for at least $3 \mathrm{~h}$.

\section{$\triangle$ CRITICAL STEPS}

Transformation and analysis of the clones

Screening for GFP reassembly
9| Transform the ligated products by mixing $1 \mu$ of each reaction (from step 8) with $50 \mu$ l electrocompetent E. coli DH10B. Transform, preferably by electroporation (2-mm cuvette at 2.5 $\mathrm{kV}$ ), and quench with $1 \mathrm{ml}$ of $2 \mathrm{YT}$. Plate the pET1la-link-NGFP transformations immediately onto LB agar containing $100 \mu \mathrm{g} / \mathrm{ml}$ ampicillin. Incubate the pMRBAD-link-CGFP transformations with shaking ( $>200$ r.p.m.) at $37^{\circ} \mathrm{C}$ for at least $1 \mathrm{~h}$, then plate onto selective agar medium containing $35 \mu \mathrm{g} / \mathrm{ml}$ kanamycin.

10| Select several colonies, grow each in $5 \mathrm{ml}$ of $2 \mathrm{YT}$ medium with the appropriate antibiotic and prepare plasmid DNA from $1.5 \mathrm{ml}$ of culture using a standard miniprep procedure.

11| Verify the presence of the insert by digesting $10 \mu$ of each miniprep with the appropriate pair of restriction enzymes and separating the fragments by electrophoresis through an agarose gel. Alternatively, the loss of the unique linker restriction sites can also be used as a diagnostic.

12 Confirm that the GFP fusions are the correct ones by sequencing the clones using appropriate primers (Fig. 1a).

In the specific case of pMRBAD-CGFP constructs, which we prefer for libraries, we perform colony PCR with primers 5'-tagcggatcctacctgacgc-3' and 5'-ttcgggctttgttagcagcc- $3^{\prime}$. Reactions are performed in a 96-well plate and are cleaned up for sequencing by treatment with ExoSAP-IT at $37^{\circ} \mathrm{C}$ for $15 \mathrm{~min}$, followed by $80^{\circ} \mathrm{C}$ for $20 \mathrm{~min}$.

13| Transform the verified plasmid constructs into a DE3 host (we use electrocompetent BL21). When a single pair of constructs is to be checked, simultaneous transformation of both plasmids is possible, using 1-10 ng of each construct miniprep DNA in $1 \mu$ l water. Incubate the doubly transformed cells with shaking at $37^{\circ} \mathrm{C}$ for $1 \mathrm{~h}$ and then plate them on doubly selective LB agar plates $(100 \mu \mathrm{g} / \mathrm{ml}$ ampicillin and $35 \mu \mathrm{g} / \mathrm{ml}$ kanamycin).

When the transformation efficiency is critical (for example, when one plasmid contains a library), we prepare electrocompetent cells containing the constant partner.

14| To perform the screen for GFP reassembly, plate 5-10 $\mu$ of a 1:104 dilution of a fresh overnight culture onto screening media to obtain individual colonies. We recommend marking the agar plate into quadrants, for control and experimental combinations (Fig. 2a). This allows for side-by-side comparison of bait and prey sets (Fig. $\mathbf{2} \mathbf{b}$ ). Incubate the plates either at $30^{\circ} \mathrm{C}$ overnight followed by $15-25^{\circ} \mathrm{C}$ for $1-2 \mathrm{~d}$, or continuously at $15-25^{\circ} \mathrm{C}$ for $2-3 \mathrm{~d}$. After the first day, it is advisable to seal plates with Parafilm, to prevent them from drying out.

Typical induction conditions are $10 \mu \mathrm{M}$ I PTG for pET1la-NGFP and $0.2 \%$ arabinose for pMRBAD-link-CGFP. These conditions give reproducible green-fluorescent colonies with the control leucine zipper bait and prey peptide fusions.

\section{$\triangle$ CRITICAL STEPS \\ $\Rightarrow$ TROUBLESHOOTING}


a

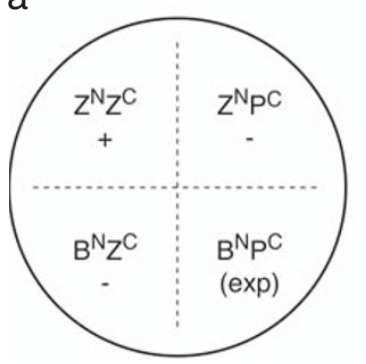

b

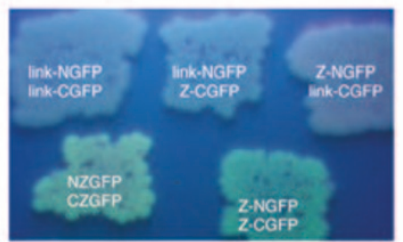

C

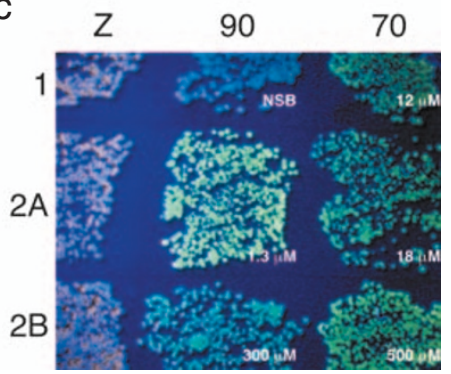

Figure 2 | (a) Schematic plate layout for screening interactions with the GFP reassembly screen. $Z^{\mathbb{N}}$ and $Z^{C}$ represent control leucine zipper constructs (positive control), and $B^{N}$ and $P C$ are the bait and prey NGFP and CGFP constructs, respectively. This arrangement provides a positive control, two negative controls and an experimental (exp) quadrant. (b) Examples of GFP reassembly with leucine zipper peptides. Top, empty vectors and single leucine zipper expression combinations do not give green fluorescence. Bottom, fluorescence observed with the original NZGFP and CZGFP constructs ${ }^{6}$ (left) and improved vectors ${ }^{7}$ (right). (c) GFP reassembly mediated by the TPRs of HOP7 . pET1la-link-NGFP constructs contained the negative control leucine zipper peptide (Z) and the C-terminal 24 residues of Hsp70 and Hsp90. pMRBAD-link-CGFP contained TPR1, TPR2A and TPR2B from HOP. Cognate interactions (70:TPR1, 90:TPR2A) are brighter than noncognate interactions (70:TPR2A, 90:TPR1), but affinities measured in vitro by surface plasmon resonance do not directly correlate to brightness. NSB, no saturating binding.

15| Observe the plates with a handheld long-wave UV lamp (365 nm) to visualize colonies that exhibit fluorescence (thus having properly reassembled GFP).

Green fluorescence under long-wave ultraviolet illumination ( $365 \mathrm{~nm}$ ) typically develops after the second day and does not improve beyond 4 days.

\section{$\Rightarrow$ TROUBLESHOOTING}

16 If fluorescent cells do not appear, select a candidate colony from those identified in step 15, and prepare a $50-\mathrm{ml}$ culture in LB, supplemented with ampicillin and kanamycin but without IPTG or arabinose. Prepare also positive (containing leucine zipper peptide) and negative (containing the empty vectors) control cultures for quantitative comparison. Grow the cultures at $37^{\circ} \mathrm{C}$ overnight in a shaking incubator

Alternatively, bacteria from an agar plate may be recovered using a plate spreader and $1 \mathrm{ml}$ of TN buffer ( $50 \mathrm{~mm}$ Tris HCl, pH 8.0; $300 \mathrm{~mm} \mathrm{NaCl}$ ). The pET1la-link-NGFP vector incorporates an N-terminal hexahistidine tag. Because GFP reassembly is effectively irreversible, and unassembled GFP-fragment fusions are typically insoluble, the reassembled fusion can be purified and concentrated in a single step from the soluble fraction of cell lysate?

17| The next day, move the flasks to $15-25^{\circ} \mathrm{C}$ and add IPTG and arabinose to the final induction concentrations (see step 14). Continue shaking for a further $2-4 \mathrm{~d}$ at $15-25^{\circ} \mathrm{C}$.

18| Harvest the cells by centrifugation, and resuspend them in $2 \mathrm{ml}$ of lysis buffer. Add $1 \mu$ leach of DNase and RNase and incubate the lysate on ice for $30 \mathrm{~min}$.

19| Split the lysate into $1 \mathrm{ml}$ aliquots and centrifuge at $4{ }^{\circ} \mathrm{C}$ for $30 \mathrm{~min}$ at maximum speed in a benchtop microcentrifuge.

20| Combine the superatant with $200 \mu \mathrm{l}$ Ni-NTA agarose slurry and mix gently at $4{ }^{\circ} \mathrm{C}$ for $1 \mathrm{~h}$. Wash the resin in a disposable standing column with $2 \mathrm{ml}$ of wash buffer and then elute His-tagged protein with wash buffer plus $300 \mathrm{mM}$ imidazole.

Fluorescence per cell culture absorbance unit ( $600 \mathrm{~nm}$ ) can be assessed quantitatively with an emission scan between 475 and $525 \mathrm{~nm}\left(\lambda_{\text {excitation }}=468 \mathrm{~nm}\right)$. Reassembled GFP variant sg100 has a $\lambda_{\text {emission }}$ at $\sim 505 \mathrm{~nm}$ 
PROBLEM

Steps 1 and $5 \mathrm{~A}$ low plasmid yield is obtained for pMRBAD-link-CGFP.

Steps 2 and $\mathbf{4}$ We get poor cloning efficiency into pET11a-link-NGFP.

\section{SOLUTION}

Vector origin of replication is p15A (low copy number). Miniprep yield is usually sufficient for sequencing. Plasmid copy number can be increased by adding chloramphenicol $(150 \mu \mathrm{g} / \mathrm{ml})$ after overnight growth and continuing growth for $8 \mathrm{~h}$. For larger-scale vector purification (midi- and maxiprep), DNA preparation by alkaline lysis/ PEG precipitation is best.

We have experienced problems digesting with BamHI Ensure that the total glycerol concentration $\varangle \%$ and incubate reaction for a maximum of $3 \mathrm{~h}$.

BamHI cannot be heat inactivated. Remove by phenol/chloroform/ isoamyl alcohol extraction. We recommend using pMRBAD-link-CGFP for efficiencysensitive cloning (for example, libraries).

Steps 14 and 15 We observe no green fluorescence or poor fluorescence when screening colonies for presence of the reassembled GFP.
Poor expression of fusions. Check for expression of GFP fusions on SDS-PAGE. Vary concentrations of inducer to obtain roughly stoichiometric levels of expression. We find that $0-20 \mu \mathrm{M}$ IPTG and $0.02-0.2 \%$ arabinose is useful. Induction of pET11a-NGFP fusions may not be necessary, because the $\mathrm{T7}$ promoter is leaky. Addition of $>0.2 \%$ arabinose does not significantly improve expression of CGFP fusions.

Configurational incompatibility between bait and prey GFP fusions. GFP fragments could interfere with bait-prey interaction. Alternatively, bait and prey may interact, but the GFP fragments may be unable to reassemble. Try increasing bait-prey-GFP spacer length (for example, through multiple GlyGlySer insertions) or swapping bait-prey vector orientation. We have successfully used spacers up to 15 amino acids in length.

Bait or prey misfolded. The analyte protein most likely to be an independently structured domain should be placed on PMRBAD-link-CGFP vector, so that the unstructured CGFP fragment follows the folded domain. We typically display short peptides and unstructured motifs as NGFP fusions. Exploring alternative GFP dissection and fragment fusion strategies $^{8}$ may be necessary.

Low reassembly efficiency. Factors such as expression level and solubility could lead to visually undetectable fluorescence in vivo. Perform expression in liquid culture and then use the NGFP His-tag to simultaneously purify and concentrate the soluble, reassembled material for quantitation in vitro. This method is very sensitive and should reveal if any reassembly (and therefore bait-prey interaction) is taking place. 


\section{CRITICAL STEPS}

Step 1 pMRBAD-link-CGFP uses the kanamycin resistance gene as a selectable marker. All transformations involving pMRBAD-CGFP constructs (steps 1 and 4) must be followed by incubation, with shaking at $37^{\circ} \mathrm{C}$ for at least $1 \mathrm{~h}$, before plating on kanamycin-containing media.

Step 4 It is important to consider carefully into which vector the bait and prey should be cloned. For each bait-prey experiment, two orientations are possible: NGFP-bait with prey-CGFP and NGFP-prey with bait-CGFP. Knowledge of the bait-prey complex topology, and the location of free $\mathrm{N}$ and Ctermini, is especially useful at this stage. Avoid fusions to the GFP fragments at the site of protein-protein interaction and consider optimizing the spacer length between the fusions and GFP fragments, if necessary. In the absence of structural information, both orientations of bait and prey should be tried.

Step 8 To optimize transformation efficiencies, empty religated vector can be eliminated by digesting the reaction with $0.5 \mu \mathrm{l}$ of restriction enzyme corresponding to the linker site removed through cloning (Xmal for pET11a-link-NGFP, Sphl for pMRBAD-link-CGFP). Incubate the reaction at 37 ${ }^{\circ} \mathrm{C}$ for $1 \mathrm{~h}$, followed by heat inactivation at $80^{\circ} \mathrm{C}$ for $20 \mathrm{~min}$. This additional step is especially useful when a low background is important (for example, when cloning libraries). The target sequence must not contain the linker restriction site that is removed through cloning.

Step 14 Incubation at $15-25^{\circ} \mathrm{C}$ is required for the development of green fluorescence. Incubation at $37^{\circ} \mathrm{C}$ alone does not produce fluorescent colonies.

Step 15 Suitable safety measures (safety glasses, gloves) should be employed when using UV light. Most brands of disposable plastic Petri dishes (for example, Falcon 1029) transmit UV light poorly. Visualization must be performed on open plates, and care should be taken in their handling.

\section{COMMENTS}

Protein fragment-reassembly screens provide a powerful alternative to the traditional yeast two-hybrid approach. Those based on GFP reassembly offer several key advantages. First, detection of interactions is direct (green fluorescence) and does not require specific subcellular localization or a chemical substrate. Because the reassembly of GFP is effectively irreversible, fluorescence tends to accumulate over time, which probably aids in the detection of weak interactions. We have successfully used the screen to detect the values of $K_{\mathrm{D}}$ between 1 $\mu \mathrm{M}$ and $1 \mathrm{mM}$. GFP also makes the screen amenable to fluorescence-activated cell sorting (FACS) procedures, which simplifies the selection of positive interaction pairs. Second, GFP expression has been documented in a wide variety of organisms, in nearly every cell type and in most subcellular locations ${ }^{9,10}$. GFP tagging often has no effect on protein function, and subcellular localization does not generally affect GFP chromophore maturation. Protein-protein interactions can therefore be studied in their native biological environment. Similar reassembly schemes have also been demonstrated for the related yellow and cyan fluorescent proteins, with alternative dissection and fusion sites within the molecule ${ }^{11,12}$. Reassembly to form hybrid fluorescent proteins, with unique spectral emission properties, opens the prospect of simultaneous detection of multiple tissue-specific expression patterns within an organism ${ }^{8}$.

\section{EXAMPLE OF APPLICATION: TETRATRI COPEPTIDE REPEAT PROTEIN-LIGAND INTERACTIONS}

Human Hsp organizing protein (HOP) contains three tetratricopeptide repeat (TPR) domains. TPR1 and TPR2A bind the C-terminal residues of Hsp70 and Hsp90, respectively. TPR2B has no known ligand. The sequences encoding TPR domains of HOP were cloned into pMRBAD-link-CGFP. The corresponding peptide ligand constructs were prepared by Klenow extension and ligated into pET11a-link-NGFP. Pairs of link-NGFP and link-CGFP were transformed into E. coli BL21 (DE3) and plated onto LB agar containing $15 \mu \mathrm{M}$ IPTG and $0.2 \%$ arabinose. In vivo-reassembled GFP (Fig. $2 c$ ) recapitulated the trends described by in vitro biophysical methods ${ }^{7}$. TPR2B gave strong green fluorescence in combination with Hsp70 and Hsp90, which is in contrast to all the $K_{D}$ values determined in vitro $(500 \mu \mathrm{M}$ and $300 \mu \mathrm{M}$, respectively). This result highlights the sensitivity of the screen to factors in addition to receptor-ligand affinity, such as construct solubility and expression level. Fluorescence intensity does not necessarily correlate quantitatively to interaction affinity. 


\section{SOURCE}

This protocol was provided directly by the authors listed on the title page. For further details on the composition of media and standard procedures, such as transformation, see Sambrook, J . \& Russell, DW. Molecular Cloning: A Laboratory Manual (Cold Spring Harbor Laboratory Press, Cold Spring Harbor, New York, USA, 2001).

Note: Supplementary information is available on the Nature Methods website.

1. Fields, S. \& Song, O. A novel genetic system to detect proteinprotein interactions. Nature 340, 245-246 (1989).

2. J oung, I.K., Ramm, E.I. \& Pabo, C.O. A bacterial two-hybrid selection system for studying protein-DNA and protein-protein interactions. Proc. Natl. Acad. Sci. USA 97, 7382-7387 (2000).

3. Pelletier, J .N., Campbell-Valois, F.X. \& Michnick, S.W. Oligomerization domain-directed reassembly of active dihydrofolate reductase from rationally designed fragments. Proc. Natl. Acad. Sci. USA 95, 12141-12146 (1998).

4. Pelletier, J .N., Arndt, K.M., Plückthun, A. \& Michnick, S.W. An in vivo library-versus-library selection of optimized proteinprotein interactions. Nat. Biotechnol. 17, 683-690 (1999).

5. J ohnsson, N. \& Varshavsky, A. Split ubiquitin as a sensor of protein interactions in vivo. Proc. Natl. Acad. Sci. USA 91, 10340-10344 (1994)

6. Ghosh, I., Hamilton, A.D. \& Regan, L. Antiparallel leucine zipperdirected reassembly: Application to the green fluorescent protein. J. Am. Chem. Soc. 122, 5658-5659 (2000).

7. Magliery, T.J . et al. Detecting protein-protein interactions with a
GFP-fragment reassembly trap: scope and mechanism. J. Am. Chem. Soc. (in the press).

8. Magliery, T.J . \& Regan, L. Reassembled GFP: Detecting proteinprotein interactions and protein expression patterns. in Green Fluorescent Protein: Properties, Applications, Protocols, edn. 2 (eds. Chalfie, M. \& Kain, S.) (J ohn Wiley \& Sons, Hoboken, New J ersey, USA, in the press).

9. Tsien, R.Y. The green fluorescent protein. Annu. Rev. Biochem. 67, 509-544 (1998).

10. Waldo, G.S., Standish, B.M., Berendzen, J . \& Terwilliger, T.C. Rapid protein-folding assay using green fluorescent protein. Nat. Biotechnol. 17, 691-695 (1999).

11. Hu, C.D., Chinenov, Y. \& Kerppola, T.K. Visualization of interactions among bZip and Rel family proteins in living cells using bimolecular fluorescence complementation. Mol. Cell $\mathbf{9}$, 789-798 (2002)

12. Hu, C.D. \& Kerppola, T.K. Simultaneous visualization of multiple protein interactions in living cells using multicolor fluorescence complementation analysis. Nat. Biotechnol. 21, 539-545 (2003). 